\title{
Screening and management of gestational diabetes in Mexico: results from a survey of multilocation, multi-health care institution practitioners
}

This article was published in the following Dove Press journal: Diabetes, Metabolic Syndrome and Obesity:Targets and Therapy

\author{
Livia Dainelli' \\ Alberto Prieto-Patron' \\ Irma Silva-Zolezzi' \\ Sandra G Sosa-Rubi ${ }^{2}$ \\ Salvador Espino y Sosa ${ }^{3}$ \\ Enrique Reyes-Muñoz ${ }^{4}$ \\ Ruy Lopez-Ridaura ${ }^{5}$ \\ Patrick Detzel'
}

'Nestlé Research Center, Lausanne, Switzerland; ${ }^{2} \mathrm{Health}$ Economics Department, National Institute of Public Health, Cuernavaca, Morelos, Mexico; ${ }^{3}$ Clinical Research Branch, National Institute of Perinatology Isidro Espinosa de los Reyes, Mexico City, CDMX, Mexico; ${ }^{4}$ Endocrinology Department, National Institute of Perinatology Isidro Espinosa de los Reyes, Mexico City, CDMX, Mexico; ${ }^{5}$ Center for Research on Population Health, National Institute of Public Health, Cuernavaca, Morelos, Mexico
Correspondence: Livia Dainelli Nestec SA, Nestlé Research Center, Route du Jorat 57, 1000 Lausanne, Switzerland

$\mathrm{Tel}+4|2| 7858204$

Email livia.dainelli@rdls.nestle.com
Purpose: To identify the most common practices implemented for the screening and treatment of gestational diabetes mellitus (GDM) and to estimate the GDM clinician-reported proportion as a proxy of the incidence in Mexico.

Materials and methods: Three hundred fifty-seven physicians in four major cities were asked about their practices regarding GDM screening, treatment, clinical exams, and health care staff involved in case of GDM diagnosis, as well as the percentage of women with GDM they care for. Data management and statistical analyses were done with Stata 13.

Results: The overall GDM clinician-reported proportion was $23.7 \%$. Regional differences were expected and consistent with the data on the epidemiology of the obesity in the country. The most common screening test was the oral glucose tolerance test $75 \mathrm{~g}$ one step ( $46.6 \%$ of total cases). Diet and exercise were sufficient to treat GDM in $40.6 \%$ of cases; the rest of the sample relied on some form of medication, especially oral hypoglycemic agents (63.0\% of cases), insulin $(22.0 \%)$, or a combination of these $(13.0 \%)$. To educate women on how to measure glycemia and eventually take medications, an average of 2-3 hours were necessary. The three most common prenatal screening tests were the "no stress", the "Doppler ultrasound", and the "biophysical profile", respectively, taken at least once by $70 \%, 60 \%$, and $45 \%$ of women. Among women who were prescribed insulin, only $37 \%$ managed to keep the initial prescribed dose during the whole pregnancy.

Conclusion: The survey confirmed the expected incidence and gave interesting results on the treatment of GDM. The current Mexican guidelines seem to have been partially implemented in practice, and a coherent national strategy for GDM is still missing. More studies are encouraged to investigate this topic, with the aim to better understand the importance of the monetary cost of GDM, which is currently underestimated.

Keywords: GDM incidence, pharmacological treatment, prenatal test

\section{Introduction}

Gestational diabetes mellitus (GDM) is defined as glucose intolerance with onset or first recognition during pregnancy. ${ }^{1}$ Worldwide, it affects about $17 \%$ of pregnancies according to the International Association of Diabetes and Pregnancy Study Groups criteria, but its incidence can substantially vary depending on maternal risk factors. ${ }^{2-4}$

In Mexico, several studies from the last 30 years reported an increasing GDM incidence ranging from $4 \%$ to over $30 \%{ }^{5-17}$ Nevertheless, the comparison of their findings is not straightforward as the diagnoses in these studies were based on different screening protocols (e.g., type of test), diagnostic criteria (e.g., American Diabetes 
Association, ${ }^{18} \mathrm{O}$ 'Sullivan and Mahan; ${ }^{19} \mathrm{IADSPG}^{20}$ ), and subpopulations (e.g., at risk or not). On the other hand, the current evidence coming from two big national surveys, the Encuesta Nacional de la Dinámica Demográfica (ENADID $)^{21}$ and the Encuesta Nacional de Salud y Nutrición (ENSANUT), ${ }^{22}$ and a cohort study, ESMaestras, ${ }^{23}$ stated a GDM incidence equal to $1.9 \%-2.3 \%, 2.22 \%-9.20 \%$, and $1.13 \%-1.61 \%$, respectively, but these data are self-reported by the mothers and are retrospective. Therefore, while they can be seen as reliable when it comes to the delivery outcomes (e.g., vaginal or cesarean), this is less the case for a correct GDM screening and diagnosis, meaning that the real GDM incidence is likely to be underreported. In addition, maternal prepregnancy overweight/obesity and hypertension are important risk factors for gestational diabetes. ${ }^{24}$ Last international official estimates stated that in Mexico, these rates are higher in the north than in the south ${ }^{25}$ and have been constantly increasing over the years, in women more than in men. ${ }^{22,26,27}$ According to ENSANUT, ${ }^{22}$ among women 15-49 years old, just before pregnancy 1 out of 3 women had a systolic blood pressure $>120$ and $3 \%$ had $>140$, more than 1 in 10 were $\geq 35$ years old, around $35 \%$ were overweight, and $31 \%$ were obese (Table 1 ).

These data are not consistent with the incidence of GDM if compared to other countries. In Italy, for example, where the overweight and obesity rate is $45.9 \%{ }^{28}$ the GDM incidence is $10.9 \%,{ }^{29}$ while in China, where this rate is $48.5 \%,{ }^{30}$ and the GDM incidence is $17.5 \% .^{31}$ Therefore, since in Mexico the overweight and obesity rate reaches $72.5 \%,{ }^{32}$ we would have expected the GDM incidence to be around $20 \%-25 \%$, substantially higher than what has been reported in the national surveys and the teachers cohort study.

In addition, neither in the literature nor in the national surveys, information is available on the items driving the cost of GDM management up, such as the treatment approach (e.g., diet and exercise), the medications prescribed (e.g., insulin), the prenatal exams recommended, and the specific health care provider interacting with pregnant women (e.g., doctors) in case of a positive GDM diagnosis. The only available information supports that in $>90 \%$ of cases, a physician will monitor the pregnancy and take care of the birth independent from the GDM diagnosis ${ }^{21-23}$ and from the health care institutions he/she works for.

The Mexican health care system is currently based on three main public health care institutions: the Ministry of Health (SSA), the Mexican Institute of Social Security (IMSS), and the Institute of Security and Social Services for State Workers (ISSSTE), which respectively insure those who do not have an official employment and employees of the private and public sectors. Each health care institution is further organized into three levels (first, second, or third) of health care (nivel de atención). In the first level, basic health services are provided. Whenever a patient requires diagnostic procedures, therapeutic treatments, and rehabilitation, he/she will be sent to the second level, consisting in the general, regional, pediatric, and maternal-infantile hospitals. The third level is a network of highly specialized hospitals with advanced technology, where complex diseases of low prevalence and/or of high risk are treated. Each doctor practicing in Mexico works in one of the three levels for one public health institution and/or in the private sector and will then be subject to their specific tariffs, constrains, and regulation, but little is known on how this affects the health care service provided.

To better understand common management practices of GDM in the three main health care institutions of Mexico and to strengthen the hypothesis of an underestimated prevalence, we performed a multicity survey involving 357 practitioners working in four Mexican urban areas.

As participation was voluntary, anonymous, and nonremunerated and because sensitive personal data were not collected or provided at any point during the survey, this study was exempt from the need for approval by an institutional review board. Moreover, in accordance with the Mexican regulations of the general health law regarding health research, the use of survey is considered as risk-free research and does not require written informed consent. ${ }^{33,34}$

Table I Risk factors for gestational diabetes in Mexican mothers by age group

\begin{tabular}{llllll}
\hline Years & $\begin{array}{l}\text { Pregnancies } \\
\text { by age (\%) }\end{array}$ & $\begin{array}{l}\text { Overweight } \\
\text { at age (\%) }\end{array}$ & $\begin{array}{l}\text { Obesity at } \\
\text { age (\%) }\end{array}$ & $\begin{array}{l}\text { Hypertension, } \\
\text { SBP > I 20 (\%) }\end{array}$ & $\begin{array}{l}\text { Hypertension, } \\
\text { SBP > I 40 (\%) }\end{array}$ \\
\hline $15-19$ & 28 & 40.3 & 36.3 & 25.8 & 1.1 \\
$20-29$ & 46.7 & 32.6 & 23.8 & 31.2 & 2.3 \\
$30-34$ & 14.4 & 35.2 & 38 & 42.1 & 3.2 \\
$35-39$ & 7.4 & 37.1 & 43 & 46.7 & 6.8 \\
$40-49$ & 3.5 & 36.7 & 45.7 & 60.4 & 14.2 \\
\hline
\end{tabular}

Abbreviation: SBP, systolic blood pressure. 


\section{Materials and methods \\ Sampling frame, data collection, and management}

Data were gathered following a prearranged questionnaire conducted during June-July 2017 by the sales force of the Maternal Nutrition Marketing division of Nestlé Mexico. The questionnaire, in Spanish (a translation in English can be found in the Supplementary material), was initially drafted by researchers from the Instituto Nacional de Salud Publica and further refined in collaboration with a team of researchers from the Nestlé Research Center in Switzerland. A pilot testing was undertaken with two gynecologists from the Instituto Nacional de Perinatología Isidro Espinosa de los Reyes.

The cross-sectional survey took place in Mexico City, Guadalajara, Monterrey, and Merida, as these cities are the most populated metropolitan zones in the central, west, north, and southeast regions respectively, and one out of four Mexican residents lives in one of these. ${ }^{35}$

The physicians involved in the survey were main health care providers in charge of caring for pregnant women in Mexico. The inclusion criteria in the study were that doctors were working in the aforementioned cities and attending women with GDM in their practice. All the physicians were asked about their practices regarding the GDM screening and management, as well as the percentage of women with GDM they care for. Some answers were digital and others were paper based, but in both cases the survey was exactly the same. Doctors in ISSSTE and SSA filled the questionnaires by themselves on the tablet of the medical delegate conducting the survey. Whenever a question was not clear, they had the possibility to ask him/her for more details. Completed questionnaires were collected at the end of each meeting. In IMSS buildings, it is not allowed to conduct external surveys. Therefore, doctors fulfilling the recruiting criteria were given paper-based questionnaires through the directors of the area, who received prior training from the medical delegate in order to be able to solve eventual doubts. Completed questionnaires were returned few days later. Answers were then imported to a database using the software "SalesForce".

\section{Data analysis}

We estimated the reported GDM incidence asking doctors the percentage of GDM cases attended in their practice over the total. We also investigated on the type of GDM screening tests more frequently used, the possible treatments available, the eventual medications prescribed if required, the medical staff involved in the measurement of levels of glycemia, the type of prenatal screening tests to verify the healthy growth of the fetus, and the doses of insulin that, on average, maintain pregnant women under controlled glycemic levels.

A quality assurance procedure was undertaken to guarantee that the data were accurately captured. Then statistical analyses were performed using Stata 13 (StataCorp. 2013. Stata Statistical Software: Release 13; StataCorp LP, College Station, TX, USA). We ran beta, logistic, Poisson, and multinomial regression models to estimate the adjusted outcome variables and test the statistical differences, choosing each time the distribution which better fitted the nature of our data. To analyze the difference in the clinician-reported proportion of GDM by city and location, for example, we followed the approach of Ferrari and Cribari-Neto. ${ }^{36}$ The data reported were between 0 and 1 , and the most adequate distribution was the beta distribution as its predictions are confined to the same range, in contrast to linear models where predictions could fall out of the realistic range of probabilities.

For the qualitative variables, such as GDM screening tests prescribed, we used multinomial logistic models, ${ }^{37}$ as the physicians reported a single choice among the four choices listed. The multinomial logistic models fit when the dependent variable takes on more than two outcomes and the outcomes have no natural ordering.

We ran logistic regressions in case of dichotomous variables, such as the type of prenatal screening tests done, whereas to estimate the number of hours spent to educate pregnant women on how to measure glycemia and manage medication, we used a Poisson regression. ${ }^{38}$ Poisson regression fits models on the number of occurrences of an event. The incidence rate is the rate at which events occur, and it can be multiplied by exposure to obtain the expected number of observed events. The comparison of rate is done calculating incidence-rate ratios.

Finally, we used the predictive values model to estimate the adjusted mean value of the GDM clinician-reported proportion by city and health care institution and the deltamethod approximation for its confidence interval. ${ }^{39,40}$

All the $p$-values used for statistical significance are indicated by one to three stars next to the estimated coefficients $\left({ }^{* * *} p<0.01,{ }^{* *} p<0.05,{ }^{*} p<0.1\right)$. In the text, if not specified otherwise, we considered statistical significance at $p<0.05$.

\section{Results}

Among the 357 doctors contacted, 307 completed the survey: 129 from SSA, 116 from IMSS, and 62 from ISSSTE. The majority of those who did not complete the questionnaire work for the IMSS, specifically to the Centro MédicoNacional de Occidente (Western National Medical Center in 
English), below a medical delegate who was in maternity leave at the time of the survey. Since people conducting external surveys are not allowed to enter the IMSS building, as explained above, it was not possible to ensure that doctors answered $100 \%$ of the questions in the form.

Almost half of the sample worked in the third (48.2\%) or in the second (43.3\%) level of health care and only a few $(6.8 \%)$ in the first. As far as their specialization is concerned, $84 \%$ were obstetricians/gynecologists, $5.9 \%$ general practitioners, $4.6 \%$ maternal-fetal experts, $1.30 \%$ gynecologistsendocrinologists, $0.98 \%$ endocrinologists, $0.33 \%$ internists, while $2.61 \%$ did not specify it.

\section{GDM clinician-reported proportion}

The total predicted GDM clinician-reported proportion was $23.7 \%$ (Table 2). Differences among institutions (lowest SSA 20.9\%; highest IMSS 27.4\%) were smaller compared with those among cities (lowest Merida 17.9\%; highest Monterrey 29.6\%).When looking at the locations and taking Mexico City as a reference, we observed a statistically significant difference with Monterrey and Guadalajara but not with Merida; while when looking at the health care institutions and taking the IMSS as a reference, only the difference with SSA was statistically significant.

\section{GDM screening test}

The current guidelines ${ }^{41}$ list the possible screening methods but they do not specifically recommend any of those. In our survey, the four proposed GDM screening tests were the Oral Glucose Tolerance Test (OGTT) with either $75 \mathrm{~g}$ (OGTT $75 \mathrm{~g}$ )

Table 2 Adjusted GDM clinician-reported proportion by city and health care institution using a beta regression

\begin{tabular}{|c|c|c|c|}
\hline & $\begin{array}{l}\text { \% GDM } \\
\text { clinician-reported } \\
\text { proportion (CI) }\end{array}$ & OR (CI) & $\begin{array}{l}\text { Frequency } \\
\text { (n) }\end{array}$ \\
\hline \multicolumn{4}{|l|}{ Cities } \\
\hline Mexico City & 21.1 (I8.4-23.8) & $\mathrm{a}$ & 149 \\
\hline Guadalajara & $28.5(23.8-33.3)$ & $1.38 * *(1.0 \mathrm{I}-\mathrm{I} .88)$ & 60 \\
\hline Monterrey & $29.6(24.6-34.6)$ & $1.53 * * *(1.16-2.05)$ & 56 \\
\hline Merida & 17.9 (I3.5-22.3) & $0.78(0.56-1.09)$ & 42 \\
\hline \multicolumn{4}{|l|}{ Institutions } \\
\hline IMSS & $27.4(24-30.7)$ & $\mathrm{a}$ & 116 \\
\hline ISSSTE & $22.4(18.3-26.6)$ & $0.960(0.70-1.31)$ & 62 \\
\hline SSA & $20.9(18-23.7)$ & $0.78 * *(0.60-0.99)$ & 129 \\
\hline All & 23.7 (21.6-25.7) & & 307 \\
\hline
\end{tabular}

Notes: $* * * p<0.01,{ }^{*} p<0.05$. Reference groups (a): Location: Mexico City; Healthcare institution: IMSS. Frequency refers to the number of doctors in each location and health care institution.

Abbreviations: GDM, gestational diabetes mellitus; IMSS, Mexican Institute of Social Security; ISSSTE, Institute of Security and Social Services for State Workers; SSA, Ministry of Health; OR, odds ratio. or $100 \mathrm{~g}$ (OGTT $100 \mathrm{~g}$ ) of glucose, and taking place at once (one step protocol) or being preceded by a $50 \mathrm{~g}$ glucose load (two steps protocol). The OGTT $75 \mathrm{~g}$ one step was reported in $46.6 \%$ of cases, the OGTT $75 \mathrm{~g}$ two steps in $23.9 \%$, while the OGTT $100 \mathrm{~g}$ in one or two steps were respectively reported in $14.4 \%$ and $15.1 \%$ of cases.

The comparison of the OGTT $75 \mathrm{~g}$ one step with the other tests among cities, taking Mexico City as a reference, showed statistically significant differences with Monterrey and Guadalajara, less with Merida. The comparison of the OGTT 75 $\mathrm{g}$ one step with the other tests among health care institutions, taking IMSS as a reference showed statistically significant differences for the OGTT $75 \mathrm{~g}$ two steps with ISSSTE and SSA, and for the OGTT $100 \mathrm{~g}$ one step with SSA (Table 3).

\section{GDM treatment and medication}

According to clinicians' opinion, an average of $40.6 \%$ of GDM cases are managed with diet and exercises only, while in the other $60 \%$ some form of medication, either insulin, oral hypoglycemic agents (OHA), or both, is added. The proposed options for medication were "insulin", "OHA", "two or more", and "other", to give doctors the possibility to express the eventual use of a different medication if this was the case. OHA (e.g., metformin) resulted to be by far the most common medication: more than $63.0 \%$ of total cases treated with medications, indeed, relied on OHA alone. Insulin alone was used in $22.0 \%$ of cases and the combination of insulin and OHA in $13.0 \%$ of cases. Only $2.0 \%$ of doctors declared to use a different medication but they did not specify which one.

While there were no big differences at institutions level (Figure 1), we found some differences when controlling per city (Figure 2): in Mexico City they rely for a quarter on a combination of OHA and insulin, while in Merida it is either one or the other; in Monterrey $<10 \%$ of cases are treated with insulin, while in Guadalajara this proportion is three times higher. However, when comparing the OHA to the other medications, we did not find any statistical significant difference but the one between Monterrey and Mexico City (Table 4).

\section{Medical staff}

Doctors were asked who are the professional figures educating women on how to measure glycemia and use medications. The options proposed were "doctor", "nurse", "other", and "unskilled assistant". According to the great majority of answers, these are nurses and doctors (Table 5). In Mexico City and Guadalajara the proportion between doctors and nurse is about $50 \%$, meaning that women have the same 


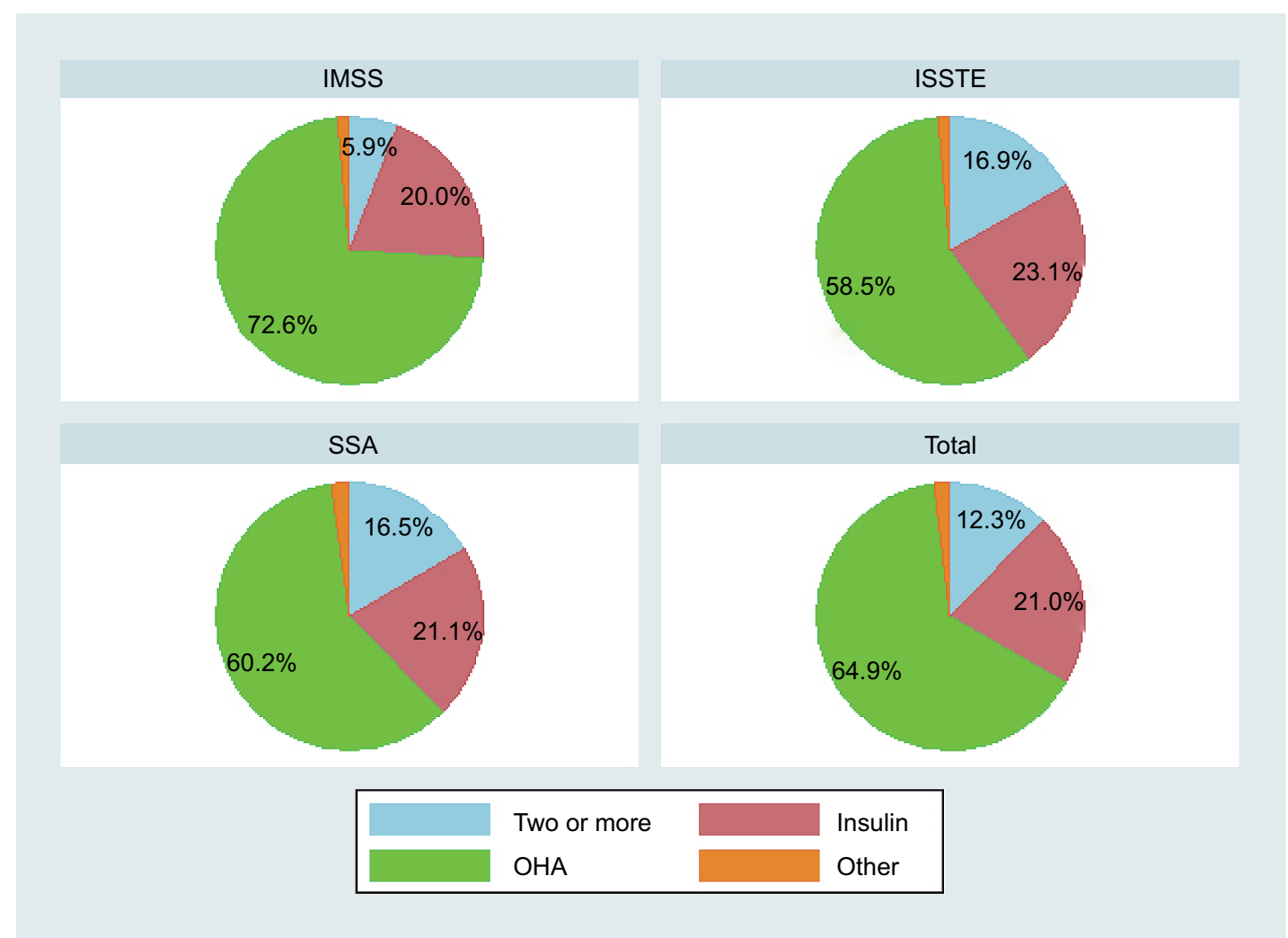

Figure I Distribution of prescribed medications by health care institution.

Abbreviations: IMSS, Instituto Mexicano del Seguro Social; ISSSTE, Instituto de Seguridad y Servicios Sociales de los Trabajadores del Estado; OHA, oral hypoglycemic agents; SSA, Secretaría de Salud.

probability of being trained by one of the two. On the contrary, in Monterrey and Merida we found remarkable differences: in Monterrey $64.8 \%$ of women are trained by a doctor and $32.8 \%$ by a nurse, while in Merida, only $19.6 \%$ of women are trained by a doctor and in $77.6 \%$ of cases this responsibility falls on nurses, and this difference is statistically significant when compared to Mexico City. Similarly, when controlling for health care institution, in the IMSS they rely more on doctors $(65.4 \%$ of cases) than on nurses for this task, while in both ISSSTE and SSA the situation is reverse, but this difference is significant only for the ISSSTE (Table 5).

Finally, the time spent for this education session is about 2-3 hours, and it does not remarkably change with the city or the health care institution, even when the differences are significant (Table 6).

\section{Prenatal tests}

Since no information is available on which type of prenatal tests women undertake, we asked doctors which test they recommend at least once during pregnancy. The four proposed options were "no stress", "Doppler ultrasound", "biophysical profile", and "other". According to the guidelines, ${ }^{41}$ all pregnant women with GDM have to have a no stress test per
Table 3 Comparison of the screening test OGTT $75 \mathrm{~g}$ one step with the others prescribed by the doctors in Mexico - multinomial logit regression

\begin{tabular}{llll}
\hline & $\begin{array}{l}\text { Is_OGTTI 00 } \\
(\mathbf{C I})\end{array}$ & $\begin{array}{l}\text { 2s_OGTT75 } \\
(\mathbf{C I})\end{array}$ & $\begin{array}{l}\text { 2s_OGTTI00 } \\
(\mathbf{C l})\end{array}$ \\
\hline Cities & & & \\
Mexico City & $\mathrm{a}$ & $\mathrm{a}$ & $\mathrm{a}$ \\
Guadalajara & $0.192^{* * *}$ & $0.277^{* * *}$ & $0.0975^{* * *}$ \\
& $(0.056-0.658)$ & $(0.120-0.640)$ & $(0.020-0.467)$ \\
Monterrey & 1.191 & $0.313^{* * *}$ & $0.306^{* *}$ \\
& $(0.535-2.653)$ & $(0.138-0.712)$ & $(0.113-0.827)$ \\
Merida & $3.245^{* *}$ & 1.986 & 1.263 \\
& $(1.205-8.743)$ & $(0.794-4.968)$ & $(0.437-3.655)$ \\
Institutions & & & \\
IMSS & $\mathrm{a}$ & $\mathrm{a}$ & $\mathrm{a}$ \\
ISSSTE & 0.759 & $0.397^{* *}$ & 1.568 \\
& $(0.307-1.879)$ & $(0.161-0.980)$ & $(0.569-4.325)$ \\
SSA & $0.407^{* *}$ & $0.528^{*}$ & 1.105 \\
& $(0.184-0.900)$ & $(0.268-1.042)$ & $(0.447-2.728)$ \\
\hline
\end{tabular}

Notes: $* * * p<0.01, * * p<0.05,{ }^{*} p<0.1$. Reference groups (a): Location: Mexico City; Healthcare institution: IMSS.

Abbreviations: IMSS, Instituto Mexicano del Seguro Social; ISSSTE, Instituto de Seguridad y Servicios Sociales de los Trabajadores del Estado; OGTT, oral glucose tolerance test; SSA, Secretaría de Salud.

week since the 32 nd week until delivery, to monitor how the fetal heart rate responds to the baby's movements. The other tests are recommended only if necessary; the Doppler 


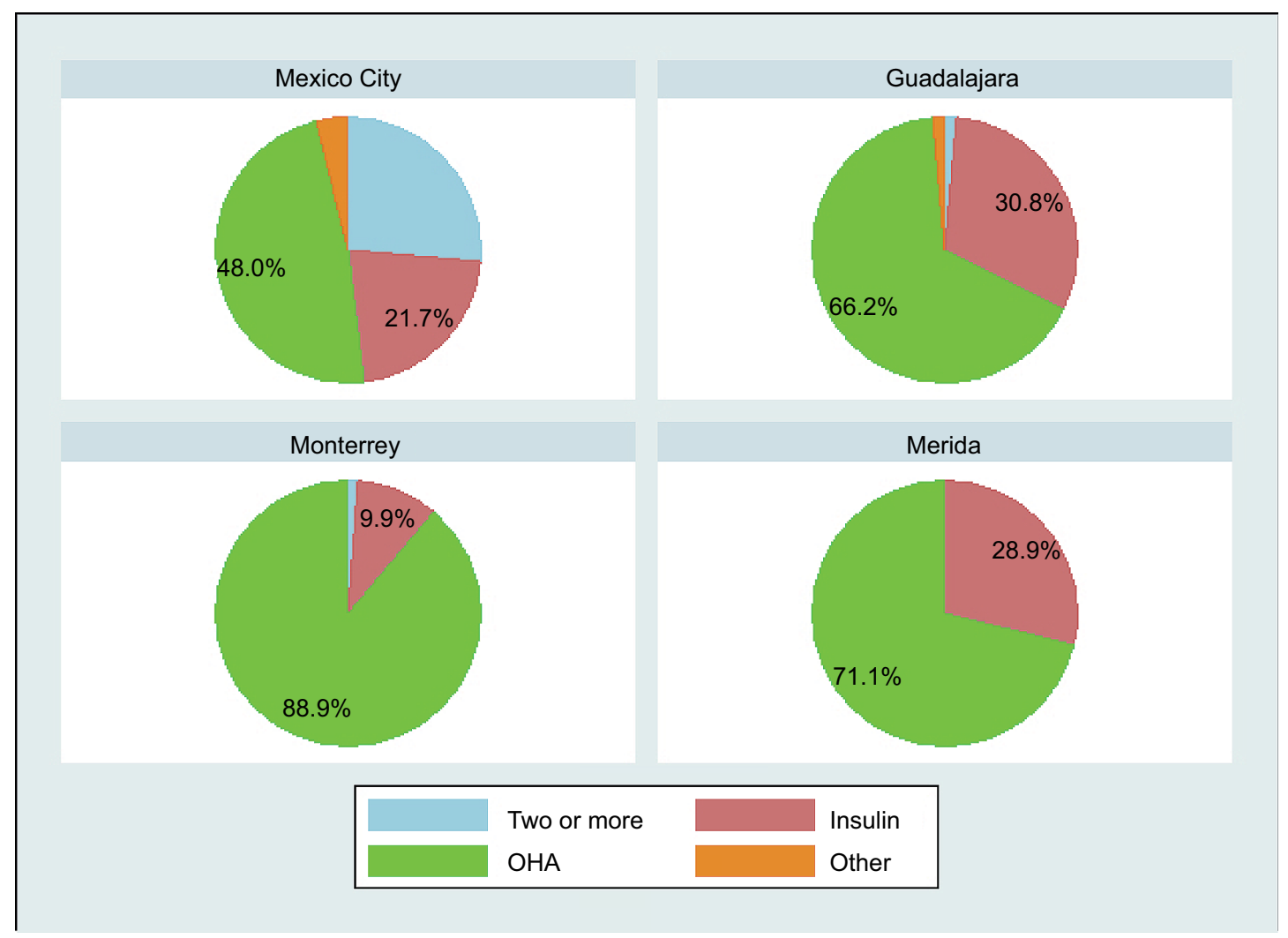

Figure 2 Distribution of prescribed medications by city.

Notes: However, when comparing the OHA to the other medications, we did not find any statistically significant difference but the one between Monterrey and Mexico City (Table 4).

Abbreviation: OHA, oral hypoglycemic agents.

Table 4 Comparison of the treatment OHA with the others reported by the doctors in Mexico - multinomial logit regression

\begin{tabular}{|c|c|c|c|}
\hline & $\begin{array}{l}\text { Two or more } \\
\text { (p-value) }\end{array}$ & $\begin{array}{l}\text { Insulin } \\
\text { (p-value) }\end{array}$ & $\begin{array}{l}\text { Others } \\
\text { (p-value) }\end{array}$ \\
\hline \multicolumn{4}{|l|}{ Cities } \\
\hline Mexico City & $\mathrm{a}$ & a & a \\
\hline Guadalajara & $2.84 \mathrm{e}-08(0.989)$ & $1.024(0.952)$ & $0.306(0.338)$ \\
\hline \multirow[t]{2}{*}{ Monterrey } & $0.0285^{* * *}$ & $0.242^{* * *}$ & $2.10 \mathrm{e}-08(0.995)$ \\
\hline & $(0.000600)$ & $(0.002 \mid 4)$ & \\
\hline Merida & $2.50 \mathrm{e}-08(0.99 \mathrm{I})$ & $0.840(0.664)$ & $2.97 e-08(0.997)$ \\
\hline \multicolumn{4}{|l|}{ Institutions } \\
\hline IMSS & $\mathrm{a}$ & $\mathrm{a}$ & $\mathrm{a}$ \\
\hline ISSSTE & I.I45 (0.807) & $1.228(0.633)$ & $0.648(0.747)$ \\
\hline SSA & $1.254(0.643)$ & I.I $63(0.662)$ & $0.995(0.996)$ \\
\hline
\end{tabular}

Notes: $* * * p<0.01$. Reference groups (a): Location: Mexico City; Healthcare institution: IMSS.

Abbreviations: IMSS, Mexican Institute of Social Security; ISSSTE, Institute of Security and Social Services for State Workers; SSA, Ministry of Health; OHA, oral hypoglycemic agents.

ultrasound is normally performed on pregnant women with GDM if they suffer from other specific conditions at the same time (e.g., arterial hypertension and nephropathy), while the biophysical profile is required at week 32 of pregnancy only if the doctor suspects about the fetal health.
In our survey, doctors generally prescribed the no stress test to $70 \%$ of women, the Doppler ultrasound to $60 \%$, and the biophysical profile to $45 \%$, with some differences when controlling per city and health care institution (Table 7). In Guadalajara, for example, all tests were less common than in Mexico City and Monterrey, while in Merida the Doppler ultrasound was considerably less common than in the other cities. When looking at the health care institutions, some significant differences have been found between IMSS and SSA, but not between IMSS and ISSSTE.

When asked how many times respondents prescribed these prenatal tests within the whole pregnancy, doctors answered on average 5.9 times for the stress test, 1.4 times for the biophysical profile, and twice for the Doppler ultrasound (Table 8). All tests were on average more common for women covered by ISSSTE more than other health care institutions, as expected.

\section{Dose of insulin}

National guidelines ${ }^{41}$ state that the initial dose of rapid and/ or intermediate (neutral protamine hagedorn [NPH]) acting 
Table 5 Adjusted percentage of medical staff educating pregnant women with GDM on how to measure glycemia and manage medication - multinomial logit regression

\begin{tabular}{|c|c|c|c|c|c|}
\hline & $\begin{array}{l}\text { Nurse } \\
\%(\mathrm{Cl})\end{array}$ & $\begin{array}{l}\text { Doctor } \\
\%(\mathrm{Cl})\end{array}$ & $\begin{array}{l}\text { Others } \\
\%(\mathrm{Cl})\end{array}$ & $\begin{array}{l}\text { Nurse vs doctor } \\
\text { OR }(\mathrm{Cl})\end{array}$ & $\begin{array}{l}\text { Nurse vs other } \\
\text { OR }(\mathrm{Cl})\end{array}$ \\
\hline \multicolumn{6}{|l|}{ Cities } \\
\hline Mexico City & $42.6(35-50.1)$ & $52.6(44.8-60.4)$ & $4.8(I . I-8.5)$ & $\mathrm{a}$ & $\mathrm{a}$ \\
\hline Guadalajara & $58.6(36.5-80.6)$ & $36.7(15.5-58)$ & $4.7(0-13.8)$ & $0.46(0.17-1.4)$ & $0.67(0.06-7.10)$ \\
\hline Monterrey & $32.8(22 . I-43.4)$ & $64.8(54-75.5)$ & $2.5(0-5.9)$ & I.68 (0.884-3.2) & $0.68(0.125-3.7)$ \\
\hline Merida & $77.6(65.3-89.9)$ & $19.6(8-31.3)$ & $2.8(0-8.2)$ & $0.170 * * *(0.06-0.4 I)$ & $0.28(0.03-2.56)$ \\
\hline \multicolumn{6}{|l|}{ Institutions } \\
\hline IMSS & 30 (20.9-39) & $65.4(56-74.8)$ & $4.6(0.1-9.1)$ & $\mathrm{a}$ & $\mathrm{a}$ \\
\hline ISSSTE & $57(44.5-69.4)$ & $43(30.6-55.5)$ & Nil & $0.30 * * *(0.144-0.64)$ & Nil \\
\hline SSA & $61.8(52.9-70.6)$ & $32.9(24.5-4 \mid .2)$ & $5.4(I-9.7)$ & $0.20 * * *(0.1-0.4)$ & $0.52(0.12-2.1)$ \\
\hline All & $47.9(4 I .8-54.1)$ & 48 (4I.9-54.I) & $4.1(1.3-6.8)$ & & \\
\hline
\end{tabular}

Notes: $* * * p<0.0$ I. Reference groups (a): Location: Mexico City; Healthcare institution: IMSS.

Abbreviations: GDM, gestational diabetes mellitus; IMSS, Mexican Institute of Social Security; ISSSTE, Institute of Security and Social Services for State Workers; SSA, Ministry of Health; OR, odds ratio.

Table 6 Adjusted average hours spent by medical staff educating pregnant women with GDM on how to measure glycemia and manage medication - Poisson regression

\begin{tabular}{lll}
\hline & Mean hours $(\mathbf{n})(\mathbf{C l})$ & $\begin{array}{l}\text { Coefficients } \\
\text { (p-value) }\end{array}$ \\
\hline Cities & & \\
Mexico City & $3.06(2.77-3.35)$ & $\mathrm{a}$ \\
Guadalajara & $2.23(1.82-2.64)$ & $0.729^{* * *}(0.00404)$ \\
Monterrey & $2.17(1.79-2.55)$ & $0.708^{* * *}(0.000791)$ \\
Merida & $2.53(2.05-3.01)$ & $0.826^{*}(0.0761)$ \\
Institutions & & \\
IMSS & $2.86(2.51-3.21)$ & $\mathrm{a}$ \\
ISSSTE & $2.94(2.52-3.37)$ & $1.029(0.776)$ \\
SSA & $2.37(2.11-2.63)$ & $0.828^{* *}(0.0289)$ \\
All & $2.66(2.48-2.84)$ & \\
\hline Nosi
\end{tabular}

Notes: ${ }^{* * *} p<0.01, * * p<0.05,{ }^{*} p<0.1$. Reference groups (a): Location: Mexico City; Healthcare institution: IMSS.

Abbreviations: GDM, gestational diabetes mellitus; IMSS, Mexican Institute of Social Security; ISSSTE, Institute of Security and Social Services for State Workers; SSA, Ministry of Health.

insulin is 0.2 units $/ \mathrm{kg}$ every day. According to the survey results, the proportion of patients the clinician perceived to be able to keep this dose during the whole pregnancy without increasing it was $37.5 \%$, more exactly $46.2 \%$ in Mexico City, $32.2 \%$ in Guadalajara, and $28.5 \%$ in Monterrey (Table 9). These numbers reflect the differences in treatment paths: the more frequent was the use of insulin, or a combination of it, as the first treatment (about $50 \%$ of cases in Mexico City, $30 \%$ in Guadalajara, and $10 \%$ in Monterrey), the more likely to stick to the initial dose during the whole pregnancy, with the exception of Merida, where even if about $30 \%$ of cases are treated with insulin as the first treatment, only $26.4 \%$ of women could keep the initial dose during the whole pregnancy.

On the other hand, no major differences were found in the answers from the health care institutions, as there were no big differences in the treatment prescribed at first (OHA, insulin, or both), consistent with the fact that internal recommendations by health care institution do not exist and treatments are chosen according to doctor's preferences. However, SSA has more restrictions than IMSS and ISSSTE in the prescription of medicines and this explains why, when asked about the eventual prescription of an additional insulin dose, doctors from both IMSS and ISSSTE were more likely to increase the dose of NPH than the doctors from SSA. Overall, the average additional doses prescribed were about 2.9 units/ $\mathrm{kg}$ for the rapid acting insulin and 5.9 units $/ \mathrm{kg}$ for the NPH.

\section{Discussion}

To our knowledge, this is the first study aiming to identify the most common practices implemented for the GDM screening and treatment in Mexico. The GDM clinicianreported proportion of $23.7 \%$ is consistent with what could have been predicted considering the elevated frequency of risk factors in Mexico, and in line with previous publications in this population showing incidences of $17.2 \%{ }^{10}$ and $10.3 \%{ }^{15}$ with the ADA 2004 criteria, ${ }^{18}$ and of $30.1 \%{ }^{15}$ with the IADSPG criteria. ${ }^{20}$

Regional differences in the GDM clinician-reported proportion were expected (lowest Merida 17.6\%; highest Monterrey 29.6\%) and are consistent with the representative data on the epidemiology of the obesity in the country, reporting a higher incidence of obesity in the north (37.2\%) than in the south $(31.6 \%)$, with Mexico city $(33.9 \%)$ and the center of the country (30.3\%) being midway. ${ }^{25}$ This is further supported by the SSA data reporting the lowest GDM clinician-reported proportion (20.9\%) in line with the lowest prevalence of obesity (42\%) compared with IMSS (48.8\%) and ISSSTE (54.9\%). ${ }^{22}$ However, in our results, the GDM 
Table 7 Adjusted percentage of women who were prescribed different types of prenatal tests - logistic regression

\begin{tabular}{|c|c|c|c|c|c|c|}
\hline & \multicolumn{2}{|l|}{ No stress test } & \multicolumn{2}{|c|}{ Doppler ultrasound } & \multicolumn{2}{|c|}{ Biophysical profile } \\
\hline & $\%(\mathrm{Cl})$ & OR (Cl) & $\%(\mathrm{Cl})$ & OR (Cl) & $\%(\mathrm{Cl})$ & OR (CI) \\
\hline \multicolumn{7}{|l|}{ Cities } \\
\hline Mexico City & 72.7 (65.5-8) & a & $71.3(63.9-78.7)$ & a & $53.8(45.8-61.9)$ & $\mathrm{a}$ \\
\hline Guadalajara & $35.9(24.3-47.6)$ & $0.30 * * *(0.15-0.6)$ & $45.3(33.1-57.5)$ & $0.295 * * *(0.14-0.6)$ & $18.8(9.3-28.2)$ & $0.122^{* * *}(0.05-0.27)$ \\
\hline Monterrey & $73.7(63.9-83.5)$ & $1.350(0.68-2.67)$ & $65.8(55.1-76.4)$ & $0.715(0.38-1.34)$ & $72.4(62.5-82.2)$ & $1.799 *(0.95-3.4)$ \\
\hline Merida & $97.7(93.2-99.9)$ & $18.13^{* * *}(2.39-13)$ & $30.2(16.6-43.9)$ & $0.175 * * *(0.08-0.37)$ & $27.9(|4.7-4| .1)$ & $0.273^{* * *}(0.12-0.58)$ \\
\hline \multicolumn{7}{|l|}{ Institutions } \\
\hline IMSS & $56(48.3-63.6)$ & a & $56.7(48.7-64.8)$ & a & $51.5(44.3-58.7)$ & a \\
\hline ISSSTE & $80(70.6-89.4)$ & $1.80(0.79-4.09)$ & $55.4(44-66.8)$ & $0.68(0.33-1.38)$ & $52.3(40.7-63.9)$ & $0.61(0.29-1.25)$ \\
\hline SSA & $77.2(70.2-84.2)$ & $2.12^{* *}(1.14-3.9)$ & $64.6(56.6-72.5)$ & $0.99(0.56-1.75)$ & $41.7(33.6-49.8)$ & $0.37 * * *(0.20-0.69)$ \\
\hline All & $69(64.5-73.6)$ & & $59.5(54.4-64.6)$ & & $47.9(42.9-52.8)$ & \\
\hline
\end{tabular}

Notes: $*^{* *} p<0.01, * * p<0.05, * p<0$. I. Reference groups (a): Location: Mexico City; Healthcare institution: IMSS.

Abbreviations: IMSS, Mexican Institute of Social Security; ISSSTE, Institute of Security and Social Services for State Workers; SSA, Ministry of Health; OR, odds ratio.

Table 8 Average number of prenatal screening tests

\begin{tabular}{llll}
\hline & $\begin{array}{l}\text { No } \\
\text { stress }\end{array}$ & $\begin{array}{l}\text { Doppler } \\
\text { ultrasound }\end{array}$ & $\begin{array}{l}\text { Biophysical } \\
\text { profile }\end{array}$ \\
\hline Cities & & & \\
Mexico City & 6.2 & 2.6 & 1.7 \\
Guadalajara & 2.3 & 1.1 & 0.3 \\
Monterrey & 4.2 & 2.3 & 2.4 \\
Merida & 12.7 & 1.1 & 1.0 \\
Institutions & & & \\
IMSS & 4.7 & 1.7 & 1.5 \\
ISSSTE & 7.9 & 2.2 & 1.8 \\
SSA & 6.1 & 2.2 & 1.2 \\
All & 5.9 & 2.0 & 1.4 \\
\hline
\end{tabular}

Abbreviations: IMSS, Mexican Institute of Social Security; ISSSTE, Institute of Security and Social Services for State Workers; SSA, Ministry of Health.

Table 9 Clinician-reported proportion of women who do not increase the initial dose of insulin and eventual increment

\begin{tabular}{llll}
\hline & $\begin{array}{l}\text { No increase } \\
\text { (\%) }\end{array}$ & $\begin{array}{l}\text { Rapid insulin } \\
\text { (units/kg) }\end{array}$ & $\begin{array}{l}\text { NPH } \\
\text { (units/kg) }\end{array}$ \\
\hline Cities & & & \\
Mexico City & 46.2 & 2.4 & 5.4 \\
Guadalajara & 32.2 & 2.6 & 2.7 \\
Monterrey & 28.5 & 4.2 & 2.1 \\
Merida & 26.4 & 3.8 & 16.9 \\
Institutions & & & \\
IMSS & 35.6 & 3.6 & 5.3 \\
ISSSTE & 36.0 & 2.8 & 11.5 \\
SSA & 40.0 & 2.4 & 3.9 \\
All & 37.5 & 2.9 & 5.9 \\
\hline
\end{tabular}

Abbreviations: IMSS, Mexican Institute of Social Security; ISSSTE, Institute of Security and Social Services for State Workers; SSA, Ministry of Health; NPH, neutral protamine hagedorn.

clinician-reported proportion was higher in the IMSS (27.4\%) than in the ISSSTE (22.4\%).

Although all the four options of GDM screening test proposed are accepted according to local guidelines, ${ }^{41} 46.6 \%$ of the survey sample declared to use the OGTT $75 \mathrm{~g}$ one step, in line with the international recommendations $\mathrm{s}^{20}$ and protocols implemented in countries such as Italy and China. ${ }^{42,43}$

Interestingly, a major difference against Italy and China is that in Mexico GDM mothers seem to more directly use a pharmacological approach rather than a staged approach. In Italy and China, the success rate of nonpharmacological treatment is higher than in Mexico, and diagnosed GDM mothers will be treated only with insulin. ${ }^{44-46}$ In our sample, data indicate that the use of OHA was preferred to insulin, even if according to Mexican guidelines insulin should be first choice of treatment and metformin and glyburide could be used only as second alternatives. ${ }^{36}$ This happened, regardless of existing controversy on the use of OHA during pregnancy, for example UK (The National Institute for Health and Care Excellence [NICE], guidelines 2008 and 2015) stating that insulin and metformin are both effective for glycemic control, ${ }^{47}$ while the American Diabetes Association recommends the use of insulin as the first line of pharmacologic treatment. ${ }^{48}$ It is reassuring that in a study from 2008 taking place in 10 New Zealand and Australian urban obstetrical hospitals, authors found women with GDM using metformin (alone or with supplemental insulin in $46.3 \%$ of cases) not experiencing increased perinatal complications as compared with insulin and actually preferring metformin to insulin treatment. ${ }^{49}$ The observed high proportion of doctors indicating women to take OHA in Mexico could be related to their lower price compared with insulin or to the preference for this type of treatment.

The prenatal tests performed in Mexico during pregnancy, such as the no stress test for all women suffering from GDM and the Doppler ultrasound only in specific high-risk cases, are consistent with available literature and guidelines from other countries. ${ }^{50-52}$ 
Overall, the guidelines ${ }^{41}$ seem partially implemented, which is reasonable given the short time since their introduction (November 2016). For example, the percentages of prenatal tests done are in line with recommendations, whereas OHA (metformin) is the most common pharmacological treatment when it should be insulin. Important to note is that across the country, the use of different diagnosis criteria and of four screening strategies reflects the lack of adoption of a coherent national strategy for GDM in Mexico.

\section{Strengths and limitations}

The strength of this study is the different point of view adopted. Previous studies reporting the incidence of GDM were either clinical studies or self-reported surveys filled by women; this is the first study reporting the perception of the health care professionals. For the same reason, it gives insight into the health care service provided in the GDM management and treatment and allows to compare official guidelines with reality to investigate how well these are implemented.

The main limitations of this study are as follows: 1) the self-reported nature of the survey, which may lead to recall bias or to an inaccurate representation of the results; 2) the sample, for its nonrepresentativeness of the country; 3 ) the possible misinterpretation of the defined population by the doctors (the questionnaire was asking for general population whereas guidelines tend to focus on women at risk, potentially creating in this latter case a small upward bias in the clinician-reported proportion); and 4) the lack of information on the precise diagnosis criteria/thresholds used.

\section{Conclusion}

The survey confirmed the expected incidence and gave insight into the particular and evolving practices for the treatment/ management of GDM in Mexico. Moreover, in our sample, only $40.6 \%$ of women managed to treat GDM with diet and exercise only, and the great majority relied on some form of pharmacological treatment, OHA (metformin) in particular, may be due to its price, relatively lower than insulin. More studies without the aforementioned limitations are encouraged to investigate this topic further and to better understand the importance of the monetary cost of GDM, currently underestimated. This evidence could support and provide rationale for harmonizing the health care service provided across the country and different health care systems.

\section{Acknowledgment}

The authors deeply thank Nestlé Nutrition Mexico for collecting the data and facilitating the study organization. The study was funded by Nestlé Nutrition Mexico.

\section{Disclosure}

Livia Dainelli, Alberto Prieto-Patron, Irma Silva-Zolezzi, and Patrick Detzel are Nestlé employees. The other authors report no conflicts of interest in this work.

\section{References}

1. Metzger BE, Coustan DR. Organising Committee. Summary and recommendations of the Fourth International Workshop Conference on Gestational Diabetes. Diabetes Care. 1998;21 (Suppl 2): B161-B167.

2. Coustan DR, Lowe LP, Metzger BE, Dyer AR; International Association of Diabetes and Pregnancy Study Groups. The Hyperglycemia and Adverse Pregnancy Outcome (HAPO) study: paving the way for new diagnostic criteria for gestational diabetes mellitus. Am J Obstet Gynecol. 2010;202(6):654.e1-6.

3. Avalos GE, Owens LA, Dunne F; ATLANTIC DIP Collaborators. Applying current screening tools for gestational diabetes mellitus to a European population: is it time for change? Diabetes Care. 2013;36(10): 3040-3044.

4. Silva-Zolezzi I, Samuel TM, Spieldenner J. Maternal nutrition: opportunities in the prevention of gestational diabetes. Nutr Rev. 2017;75 (Suppl1):32-50.

5. Forsbach G, Contreras-Soto JJ, Fong G, Flores G, Moreno O. Incidence of gestational diabetes and macrosomic newborns in a Mexican population. Diabetes Care. 1988;11(3):235-238.

6. Tamez Pérez HE, Rodríguez Ayala M, Treviño Hernández M, et al. Experiencia con un programa de escrutinio de diabetes gestacional [Experience with a screening program for gestational diabetes]. Rev Invest Clin. 1993;45(5):453-456. Spanish.

7. Meza E, Barraza L, Martínez G, et al. Gestational diabetes in a MexicanU.S. border population: incidence and epidemiology. Rev Invest Clin. 1995;47:433-438.

8. López-de la Peña XA, Cájero Avelar JJ, De León Romo LF. Incidence of gestational diabetes in a group of women receiving treatment at the Mexican Institute of Social Security in Aguascalientes, Mexico. Arch Med Res. 1997;28(2):281-284.

9. Espinosa de los Monteros A, Parra A, Hidalgo R, Zambrana M. The after breakfast 50-g, 1-hour glucose challenge test in urban Mexican pregnant women: its sensitivity and specificity evaluated by three diagnostic criteria for gestational diabetes mellitus. Acta Obstet Gynecol Scand. 1999;78(4):294-298.

10. Ramírez-Torres MA. Gestational diabetes mellitus. Experience at a third level hospital [Diabetes mellitus gestacional. Experiencia en una institución de tercer nivel de atención]. Ginecol Obstet Mex. 2005;73(9):484-491. Spanish.

11. Hernández MÁH, Aldana FJH, Tenorio EFB, Martínez MTG. Prevalencia de diabetes mellitus gestacional en el Hospital Juárez de México. Rev Hosp Juá Méx. 2010;77(2):123-128.

12. López Caudana AE, López Ridaura R, González Villalpando C, et al. Prediction of alterations in glucose metabolism by glucose and insulin measurements in early pregnancy. Arch Med Res. 2011;42(1):70-76.

13. Dueñas-García OF, Ramírez-Torres A, Diaz-Sotomayor M, Rico-Olvera H. Resultados perinatales de pacientes con diabetes gestacional diagnosticada con tres métodos diferentes [Perinatal outcomes of patients with gestational diabetes diagnosed by three different methods]. Ginecol Obstet Mex. 2011;79(7):411-418.Spanish.

14. Reyes-Muñoz E, Castellanos-Barroso, Ramírez-Eugenio BY, et al. The risk of gestational diabetes mellitus among Mexican women with a history of infertility and polycystic ovary syndrome. FertilSteril.2012;97(6):1467-1471.

15. Reyes-Muñoz E, Parra A, Castillo-Mora A, Ortega-González C. Effect of the diagnostic criteria of the International Association of Diabetes and Pregnancy Study Groups on the Incidence of Gestational Diabetes Mellitus in Urban Mexican Women: a Cross-Sectional Study. Endocr Pract. 2012;18(2):146-151. 
16. Huerta-Chagoya A, Vázquez-Cárdenas $\mathrm{P}$, Moreno-Macías H, et al. Genetic determinants for gestational diabetes mellitus and related metabolic traits in Mexican women. PLoS One. 2015;10(5): e0126408.

17. Hernández-Higareda S, Omar-AlejandroPérez-Pérez, Luz-Ma-AdrianaBalderas-Peña, et al. Enfermedades metabólicas maternas asociadas a sobrepeso y obesidad pregestacional en mujeres mexicanas que cursan con embarazo de alto riesgo. Cirugía y Cirujanos. 2017;85(4):292-298.

18. American Diabetes Association. Gestational diabetes mellitus. Diabetes Care. 2004;27 (Suppl 1):S88-S90.

19. O'Sullivan JB, Mahan CM. Criteria for the oral glucose tolerance test in pregnancy. Diabetes. 1964;13:278-285.

20. Metzger BE, Gabbe SG, Persson B, et al. International Association of Diabetes and Pregnancy Study Groups Consensus Panel. International association of diabetes and pregnancy study groups recommendations on the diagnosis and classification of hyperglycemia in pregnancy. Diabetes Care. 2010;33(7):676-682.

21. Encuesta Nacional de Dinámica Demográfica (ENADID): panorama sociodemográfico de México (2009). Encuesta Nacional de Dinámica Demográfica. Instituto Nacional de Estadística y Geografía, Consejo Nacional de Población. México: INEGI, c2011. Available from: http:// www.beta.inegi.org.mx/proyectos/enchogares/especiales/enadid/2009/ default.html. Accessed December 21, 2017.

22. Gutiérrez JP, Rivera-Dommarco J, Shamah-Levy T, Villalpando-Hernández S, Franco A, Cuevas-Nasu L, Romero-Martínez M, HernándezÁvila M. Encuesta Nacional de Salud y Nutrición 2012. Resultados Nacionales. Cuernavaca, México: Instituto Nacional de Salud Pública, 2012. http://ensanut.insp.mx/informes/ENSANUT2012ResultadosNacionales.pdf

23. Estudio de la Salud de las Maestras (ESMaestras). Instituto Nacional de Salud Pública. Available from: https://www.insp.mx/centros/saludpoblacional/enlaces/esmaestras-521.html. Accessed December 21, 2017.

24. Spaight C, Gross J, Horsch A, Puder JJ. Gestational diabetes mellitus. In Novelties in Diabetes. Karger Publishers: Basel, Switzerland; 2016;31:163-178.

25. Dávila-Torres J, González-Izquierdo JJ, Barrera-Cruz A. Obesity in México. Rev Med Inst Mex Seguro Soc. 2015;53(2):240-249.

26. NCD Risk Factor Collaboration(NCD-RisC). Trends in adult body-mass index in 200 countries from 1975 to 2014: a pooled analysis of 1698 population-based measurement studies with $19 \cdot 2$ million participants. Lancet. 2016;387(10026):1377-1396.

27. OECD 2017. Available from: https://www.oecd.org/els/health-systems/ Obesity-Update-2017.pdf. Accessed December 21, 2017.

28. ISTAT 2017. Available from: Fattori di rischio per la salute: fumo, obesità, alcol e sedentarietà. https://www.istat.it/it/archivio/202040. Accessed December 21, 2017.

29. Lacaria E, Lencioni C, Russo L, et al. Selective screening for GDM in Italy: application and effectiveness of National Guidelines. J Matern Fetal Neonatal Med. 2015;28(15):1842-1844.

30. Xu W, Zhang H, Paillard-Borg S, Zhu H, Qi X, Rizzuto D. Prevalence of overweight and obesity among Chinese adults: role of adiposity indicators and age. Obes Facts. 2016;9(1):17-28.

31. Zhu WW, Yang HX, Wei YM, et al. Evaluation of the value of fasting plasma glucose in the first prenatal visit to diagnose gestational diabetes mellitus in China. Diabetes Care. 2013;36(3):586-590.

32. ENSANUT 2016. Encuesta Nacional de Salud y Nutrición de Medio Camino. Available from: http://ensanut.insp.mx/. Accessed December 21, 2017.

33. Diario Oficial de la Federación. Reglamento De La Ley General De Salud En Materia De Investigación Para La Salud. 1987. Available from: http://www.diputados.gob.mx/LeyesBiblio/regley/Reg_LGS_ MIS_orig_06ene87.pdf. Accessed December 21, 2017.
34. Diario Oficial de la Federación. Norma Oficial Mexicana NOM-012-S S A3-2012, Que establece los criterios para la ejecución de proyectos de investigación para la salud en seres humanos. Spanish.

35. SEDESOL, CEI. Delimitación de las Zonas Metropolitanas de México 2010. ConscjoNacional de Poblacion;2015:1-214.

36. Ferrari S, Cribari-Neto F. Beta regression for modelling rates and proportions. J Appl Stat. 2004;31(7):799-815.

37. Tarlov AR, Ware JE Jr, Greenfield S, Nelson EC, Perrin E, Zubkoff M. The medical outcomes study. An application of methods for monitoring the results of medical care. JAMA. 1989;262(7):925-930.

38. Cameron AC, Pravin K Trivedi. 2010. Microeconometrics Using Stata, Revised Edition. College Station, TX, USA: Stata Press. Regression Analysis of Count Data. 2nd ed. NY, USA: Cambridge University Press; 2013.

39. Joe H. Multivariate Models and Multivariate Dependence Concepts. CRC Press Company: Boca Raton, London, New York, Washington DC; 1997.

40. StataCorp. "Stata Base Reference Manual Release 14." Stata Press Publication, StataCorp LP. College Station, TX, USA 2015.

41. Guia de practica clinica Diagnostico y tratamiento de diabetes en el embarazo, CENETEC 2016. Available from: http://www.cenetecdifusion.com/CMGPC/IMSS-320-10/ER.pdf. Accessed December 21, 2017.

42. Ministry of Health (2011), Istituto Superiore di Sanità, CeVEAS (Centro per la valutazione dell'efficacia dell'assistenza sanitaria). Linee Guida Gravidanza Fisiologica (Aggiornamento 2011). Available from:http://www.salute.gov.it/imgs/c_17_pubblicazioni_1436_allegato. pdf. Accessed December 21, 2017.

43. Yang $\mathrm{H}, \mathrm{Xu} \mathrm{X}$, Wang $\mathrm{Z}$, et al. A guide for the diagnosis and treatment of pregnancy complicated with diabetes. Diabetic World. 2014;11: 489-498.

44. Xu T, Dainelli L, Yu K, et al. The short-term health and economic burden of gestational diabetes mellitus in China: a modelling study.BMJ Open. 2017;7(12):e018893.

45. Li L, Yan T, Liu J, et al. The diet and exercise intervention on patients with gestational diabetes blood sugar control. West China Med J.2014;11:2069-2072.

46. Corrado F, Pintaudi B, D'Anna R, Santamaria A, Giunta L, Di Benedetto A. Perinatal outcome in a Caucasian population with gestational diabetes and preexisting diabetes first diagnosed in pregnancy. Diabetes Metab. 2016;42(2):122-125.

47. NICE, 2015. Diabetes in pregnancy: management from preconception to the postnatal period. Available from: https://www.nice.org.uk/guidance/ng3. Accessed December 21, 2017.

48. American Diabetes Association, 2016. Management of Diabetes in Pregnancy. http://care.diabetesjournals.org/content/39/Supplement_1/ S94

49. Rowan JA, Hague WM, Gao W, Battin MR, Moore MP; MiG Trial Investigators. Metformin versus insulin for the treatment of gestational diabetes. N Engl J Med. 2008;358(19):2003-2015.

50. Borna S, Rahmani Z. A Study of Doppler ultrasound indices of spiral placental and umbilical arteries in pregnant women with singlet on pregnancy suffering type- 1 diabetes mellitus, gestational diabetes and normal pregnant women. J Appl Environ Biol Sci.2015;5(10S):436-440.

51. NICE 2016. Antenatal care for uncomplicated pregnancies. Available from: https://www.nice.org.uk/donotdo/routine-doppler-ultrasoundshould-not-be-used-in-low-risk-pregnancies. Accessed December 21, 2017.

52. Zhan Y, Xiang YM, Qi WH, Wang AM, Chen WP, Shao DH. [Remote fetal monitoring for gestational diabetes mellitus]. Acad J First Med Coll PLA. 2004;24(9):1053-1054. Chinese. 


\section{Supplementary material}

\section{Survey questionnaire}

Questionnaire directed to physicians attending women with gestational diabetes

Instructions: The purpose of these questions is to identify the most common practices in the screening and treatment of women with gestational diabetes in your institution/clinic. We recommend to answer relying only on your everyday clinical practice.

1. Which main health care institution do you work for? Please choose only one option:

A) Public institution (please specify which one):

a. SSA

b. IMSS

c. ISSSTE

d. SEDENA

e. Other:

B) Private

2a. What is the level of health care of the institution you choose? Please choose only one option:
a. $1 \mathrm{st}$
b. 2nd
c. 3 rd

2b. Which medical specialization do you have? Please choose only one option:

a. General practitioner

b. Internist

c. Endocrinologist

d. Obstetrician/gynecologist

e. Maternal-fetal expert

f. Gynecologist-endocrinologist

3a. What is the average number of women with gestational diabetes you treat per month?

a. Number:

3b. And what proportion is that compared to the total number of pregnant women you attend per month? b. $\%$ :

4. When diet and exercise are not enough, which medical treatment do you generally prescribe to women with gestational diabetes mellitus (GDM)? Please choose only one option:

a. Oral hypoglycemic agents

b. Insulin

c. Other (please specify which one):

d. Combination of two or more (please specify which one):
5. According to your experience, what is the proportion of GDM cases controlled with:

\begin{tabular}{|l|l|}
\hline & Proportion (\%) \\
\hline a. Diet and exercise & \\
\hline $\begin{array}{l}\text { b. Diet and exercise + oral hypoglycemic } \\
\text { agents }\end{array}$ & \\
\hline c. Diet and exercise + insulin & \\
\hline $\begin{array}{l}\text { d. Diet and exercise + oral hypoglycemic } \\
\text { agents + insulin }\end{array}$ & \\
\hline
\end{tabular}

6a. In case insulin/OHA or another medicine is needed, what is the average number of hours used to train women to use it?

Number of hours:

6b. Which professional figure is in charge of it? Please choose only one option:

a. Nurse

b. Doctor

c. Other

d. Unskilled assistant

7. According to your experience, what is the most common GDM screening test? Please choose only one option:

OGTT $75 \mathrm{~g} 1$ step

OGTT $75 \mathrm{~g} 2$ steps (first step with $50 \mathrm{~g}$ of glucose)

OGTT $100 \mathrm{~g} 1$ step

OGTT $100 \mathrm{~g} 2$ steps (first step with $50 \mathrm{~g}$ of glucose)

8. Which kind of prenatal test do you generally prescribe to women with GDM? You can choose more than one option. Please specify the number of times/ frequency:

a) No stress test: __ Number of times

b) Doppler ultrasound:___ Number of times:

c) Biophysical profile:___ Number of times:

d) Other (please specify):___ Frequency:

9. According to the national guidelines for the treatment of women with gestational diabetes, the initial dose of NPH or rapid insulin is 0.2 units/ $/ \mathrm{kg}$ a day. In your experience, how likely is to maintain this dose during the whole pregnancy? $\%$ :

10. Whenever required, how much is the new dose including the increment?

Dose of rapid insulin (units/kg a day):

Dose of NPH (units/kg a day): 
Diabetes, Metabolic Syndrome and Obesity: Targets and Therapy is an international, peer-reviewed open-access journal committed to the rapid publication of the latest laboratory and clinical findings in the fields of diabetes, metabolic syndrome and obesity research. Original research, review, case reports, hypothesis formation, expert opinion and commentaries are all considered for publication. The manuscript management system is completely online and includes a very quick and fair peer-review system, which is all easy to use. Visit http://www.dovepress.com/testimonials.php to read real quotes from published authors.

Submit your manuscript here: https://www.dovepress.com/diabetes-metabolic-syndrome-and-obesity-targets-and-therapy-journal 